\title{
(RE)EDUCAÇÃO AMBIENTAL PARA INFRATORES NO AMAZONAS: ESTRATÉGIAS E MACROTENDÊNCIAS PEDAGÓGICAS
}

\author{
Ivan Nunes de Souza ${ }^{1}$ \\ Maria Olívia de Albuquerque Ribeiro Simão ${ }^{2}$ \\ Adalberto Carim Antonio ${ }^{3}$ \\ Henrique dos Santos Pereira ${ }^{4}$
}

Resumo: A Educação Ambiental como alternativa penal representa uma inovação das práticas judiciais. A respeito disso, foram realizadas, no Amazonas, no período de 2004 a 2018, Oficinas de Reeducação Ambiental objetivando evitar a reincidência de crimes ambientais. Esta iniciativa se constitui em um esforço conjugado entre órgãos federais, estaduais e municipais. Este artigo analisa a estrutura metodológica e a vinculação político-pedagógica dessas Oficinas. Foram analisadas entrevistas e documentos oficiais. Os temas abordados nas Oficinas são representativos dos tipos de crimes mais praticados no período e revelam a vinculação à tendência político-pedagógica "Conservacionista" de Educação Ambiental.

Palavras-chave: Educação Ambiental; Crimes Ambientais; Penas Alternativas.

1 Mestre em Ciências do Ambiente e Sustentabilidade na Amazônia (PPGCASA/UFAM). Professor da Secretaria de Estado da Educação e Qualidade do Ensino do Amazonas e da Secretaria Municipal de Educação de Manaus. E-mail: ivan.souza@seducam.pro.br; ivan.nunes@semed.manaus.am.gov.br.

2 Doutora em Biologia de Água Doce e Pesca Interior (BADPI/INPA). Professora do Departamento de Biologia da Universidade Federal do Amazonas - UFAM. E-mail: mariaoliviar@uol.com.

${ }^{3}$ Doutor em Direito pela Universidade de Limoges na França. Juiz de Direito Titular da Vara Especializada do Meio Ambiente e Questões Agrárias (TJAM). E-mail: Adalberto.carim@tjam.jus.br.

4 Doutor em Ecologia (Pennsylvania State University, PSU, Estados Unidos). Professor da Faculdade de Ciências Agrárias da Universidade Federal do Amazonas. hpereira@ufam.edu.br 


\section{Introdução}

As Oficinas de Reeducação Ambiental se constituem em uma forma diferenciada de Educação Ambiental (EA) para cidadãos infratores que têm por objetivo evitar reincidência de crimes ambientais no Amazonas. Realizadas desde 2004, essas oficinas são coordenadas pelo Núcleo de Educação Ambiental do Instituto Brasileiro do Meio Ambiente e dos Recursos Naturais Renováveis (NEA/IBAMA-AM), em parceria com a Vara Especializada do Meio Ambiente e Questões Agrárias do Tribunal de Justiça do Amazonas (VEMAQA/TJAM); Ministério Público Federal (MPF); Ministério Público do Estado do Amazonas (MPAM); Instituto de Proteção Ambiental do Amazonas (IPAAM) e Secretaria Municipal de Meio Ambiente e Sustentabilidade (SEMMAS).

Chamou a nossa atenção, o fato dessas Oficinas ocorrerem de forma sistemática, nos últimos 14 anos, no Amazonas, a partir do esforço conjugado de palestrantes voluntários, gestores de diversos órgãos de defesa do meio ambiente e coordenadores pedagógicos, sem contar com aporte direto de recursos financeiros.

Como um processo mais amplo, as Oficinas de Reeducação Ambiental corporificam a concepção de EA prevista no Art. 3ํ da Lei 9.795 de 27 de abril de 1999, que dispõe sobre a Política Nacional de Educação Ambiental (PNEA) que, em seus incisos I, II e III incumbe tanto ao poder público, quanto às Instituições educativas e aos órgãos integrantes do Sistema Nacional do Meio Ambiente (SISNAMA), bem como às instituições públicas e privadas, a tarefa de promover, de forma integrada, ações e práticas de EA em programas que, porventura, venham a desenvolver.

Neste sentido, o IBAMA/AM, órgão executor integrante do SISNAMA, vem atuando, na coordenação pedagógica dessas Oficinas, juntamente com a VEMAQA/TJAM e outros órgãos ambientais. Os dados recolhidos junto à VEMAQA/TJAM e ao NEA/IBAMA receberam tratamento estatístico descritivo e, para análise das entrevistas, foram utilizadas técnicas de análise de conteúdo de Bardin (2011). Esses procedimentos de pesquisa foram aprovados pelo Parecer consubstanciado número: 1.300 .595 do Comitê de Ética em Pesquisa da Universidade Federal do Amazonas (CEP/UFAM), Protocolo CAAE: 49717215.0.0000.5020.

A tendência pedagógica utilizada nessa modalidade diferenciada de EA nos últimos 14 anos no Amazonas foi objeto desse estudo. Para tanto, buscou-se traçar o perfil dos educandos, descrever a estrutura metodológica utilizada nas Oficinas e verificar possíveis vinculações dos temas ambientais abordados com as vertentes político-pedagógicas de Educação Ambiental. 


\section{As Oficinas de Reeducação Ambiental}

Desde sua criação, em novembro de 2004 até setembro de 2018, foram realizadas 97 edições das oficinas, que já atenderam 2.185 educandos. Entre os participantes que frequentaram as Oficinas no período $78 \%$ eram homens e $22 \%$ mulheres (Figura 1).

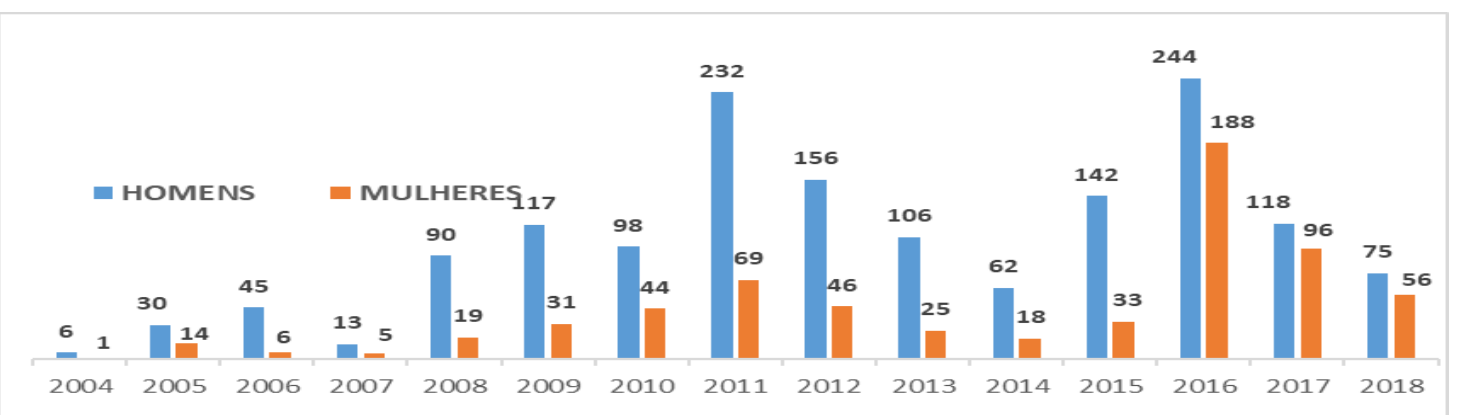

Figura 1: Distribuição entre homens e mulheres atendidos nas Oficinas de ReEducação Ambiental, por ano, no período de nov./2004 a set./2018. $\mathrm{N}=2.185$.

Fonte: Dados da sistematização da pesquisa.

Os crimes ambientais mais praticados envolvem o manuseio de madeira, lenha e carvão; construções, reformas ou obras potencialmente poluidoras, que, em sua maioria, exigem grande esforço físico, o que poderia explicar o maior número de apenados ser do sexo masculino ( $78 \%$ dos participantes das Oficinas).

A este respeito, constatou-se, a partir da análise de uma amostra de 133 processos na base de dados do Sistema de Automação Judicial - SAJ/ VEMAQA/TJAM, que abrangeu o período de fevereiro de 2013 a dezembro de 2015, que três tipos de violações representaram $50 \%$ dos crimes mais praticados pelos educandos atendidos por essas Oficinas, dentre eles o crime de recepção ou aquisição de madeira ou carvão sem a exigência de licença do vendedor foi o que obteve maior incidência $(21 \%)$ entre os crimes ambientais praticados no período. Essa tipologia criminal está prevista no Art. 46 da Lei 9.605/98, conhecida como Lei dos Crimes Ambientais (LCA). As segunda (15\%) e terceira (14\%) maiores incidências de infrações ambientais registradas no período estudado foram relativas a construções, reformas, ampliações, instalações ou funcionamento de obras ou serviços potencialmente poluidores (Art. 60 da LCA) e à morte, perseguição, caça de espécimes da fauna silvestre, nativos ou em rota migratória (Art. 29 da LCA), respectivamente.

Azevedo (2008) destaca que na aplicação da pena deve se buscar não apenas a repressão ao infrator, mas também a educação e a conscientização do mal que ele causou ao ambiente. Neste sentido, a pena deve cumprir também o papel de despertar a consciência do cidadão infrator de sua responsabilidade perante o meio ambiente.

revista brasileira

educação

ambiental 
A participação na Oficina de Reeducação Ambiental é aplicável nos casos de crimes ambientais, prescritos pela Lei Federal № 9.605/1998, em sintonia com o que determina o Art. $89, \S 2^{\circ}$ da Lei 9.099/95 e ocorre mediante a prévia aceitação da transação penal por parte dos infratores.

Lecey (2007) salienta que o aprimoramento das medidas alternativas ocasionado pela LCA fez da transação penal e da suspensão condicional do processo instrumentos de efetiva proteção ambiental. Neste sentido, Antonio (2006) assevera que sentenças alternativas como serviços à comunidade possuem um caráter eminentemente voltado para a Educação Ambiental, ainda que a Educação Ambiental, não seja mencionada em nenhum de seus 89 artigos. Ainda a esse respeito, o autor esclarece:

Na transação penal, o representante do Ministério Público poderá, com a prova da materialidade e os indícios de autoria, mediante prévia composição do dano ambiental, elaborar proposta de aplicação imediata de pena alternativa (restritiva de direito ou multa), a qual depende de aceitação do autor do fato e de seu advogado e também de homologação judicial (ANTONIO, 2006, p. 10).

Para Medeiros e Silva Neto (2008), a aplicação de sanções restritivas de direito que proporcionam a educação dos infratores ambientais parece levá-los ao despertar para uma nova postura diante das questões ambientais. Neste sentido, Foucault (2013), ao analisar a história da violência nas prisões, salienta que a imputação do encarceramento como medida punitiva acaba estimulando a reincidência criminal, que, inicialmente, pretendia combater, devolvendo à sociedade não indivíduos corrigidos, mas potenciais reincidentes.

A esse respeito, as Oficinas são identificadas como um ótimo exemplo de cumprimento de penas alternativas, com resultados benéficos oriundos da educação do infrator pelo desembargador federal aposentado Wladimir Freitas, em visita à $31^{\text {a }}$ edição das Oficinas.

Aí está um ótimo exemplo de cumprimento de penas alternativas pela prática de um crime ou mesmo dos efeitos benéficos de um acordo em Ação Civil Pública. (...) É evidente que estas sanções são muito mais úteis do que a prisão, até porque a maioria dos infratores é de pessoas que convivem na sociedade em atividade lícita. Mas, elas não podem ser uma mera fiç̧ão, algo que ninguém cumpre nem fiscaliza. $O$ sucesso delas está no acompanhamento e o complemento, na educação do infrator, para que não reincida (FREITAS, 2011). 
A EA utilizada como alternativa penal nos casos de ilícitos ambientais é uma estratégia fecunda e rica, que considera aspectos pedagógicos da pena, priorizando a transformação das penalidades em oportunidades de reflexão, construção de saberes e mudança de valores relacionados ao cuidado com o ambiente. (RIBEIRO, 2005; AZEVEDO, 2008; MEDEIROS; SILVA NETO, 2008).

Um representante do MP-AM que acompanhou de perto os primeiros anos de implantação das Oficinas destacou a ação integrada e harmônica entre as instituições judiciais e aquelas responsáveis pela defesa do meio ambiente como fundamental para os bons resultados apresentados nas Oficinas e seu caráter inovador no Brasil:

"A atuação das promotorias em harmonia com o trabalho do magistrado, que teve a sensibilidade de adotar esse método de Educação Ambiental, proveniente até mesmo da própria legislação, foi fundamental para os bons resultados apresentados. Esse esforço de ordem objetiva, juntamente com a disposição do magistrado em tornar efetiva a prestação jurisdicional, através das Oficinas, possibilitou o surgimento de algo inovador no Brasil. (...) As Oficinas foram muito bem recebidas até no meio judiciário. $O$ judiciário acolhe as partes, o Ministério Público, dentro do embasamento legal, propõe a suspensão do processo, a transação penal, que é aceita pela parte e homologada pelo juiz. O IBAMA é o órgão diretamente responsável pelo desenvolvimento das Oficinas, em parceria com as outras instituições públicas e privadas responsáveis pela defesa do meio ambiente. Essa conjugação de esforços tem apresentado excelentes resultados". (Promotor de Justiça do Meio Ambiente, em 2004. Entrevista concedida em 04/04/2016).

Segundo documentação relativa ao Programa de Educação para Infratores Ambientais do NEA/IBAMA, essas Oficinas se constituem, ainda, em uma forma diferenciada de EA para cidadãos infratores, que, muitas vezes, justificam a prática danosa pela falta de conhecimento, sem o propósito deliberado de causar dano ao ambiente.

Ao analisar o nível de escolaridade entre os participantes, o ensino médio completo foi predominante ( $45 \%$ mulheres e $37 \%$ homens). Dentre as mulheres, $10 \%$ já possuíam e $20 \%$ estavam cursando o ensino superior, enquanto que somente $13 \%$ e $6 \%$ dos homens, respectivamente, tiveram acesso a esse nível de escolaridade. Também foi constatado que $5 \%$ das mulheres e $4 \%$ dos homens não eram alfabetizados (Figura 2). 


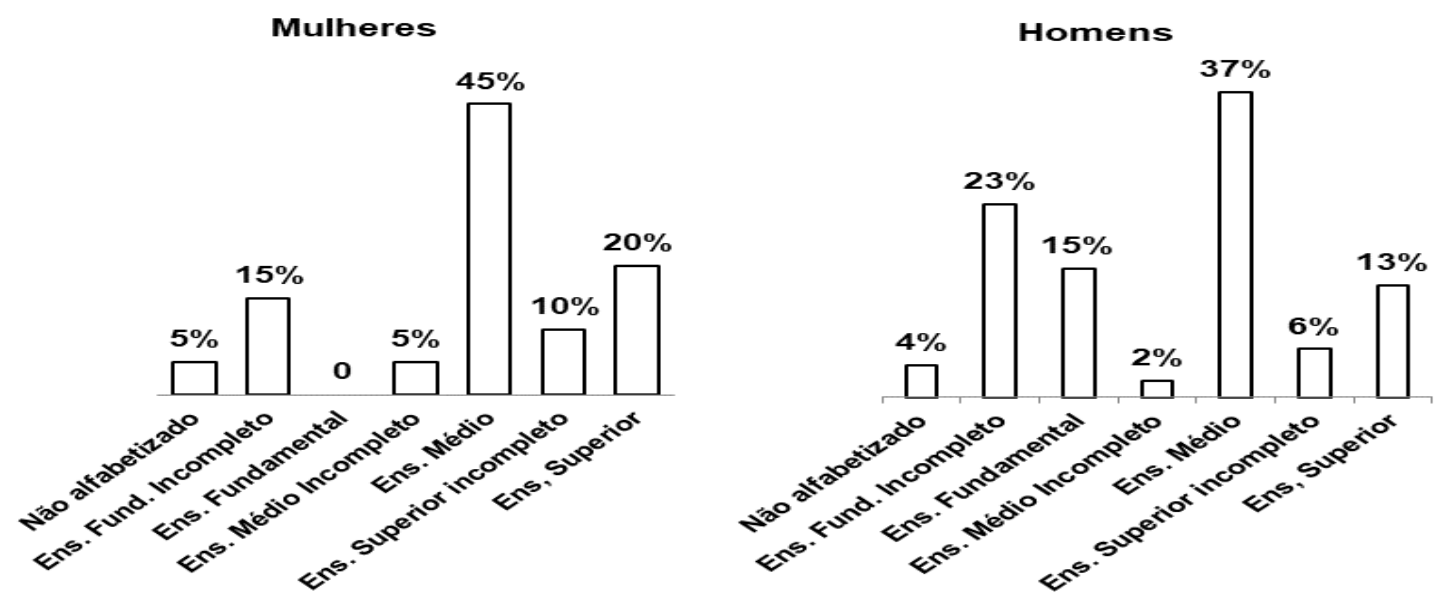

Figura 2: Distribuição entre mulheres e homens participantes das Oficinas de ReEducação Ambiental em função da escolaridade. Fonte: Dados da sistematização da pesquisa.

Verificou-se que as Oficinas são desenvolvidas conforme estrutura metodológica que cumpre o intuito de fomentar a participação pela socialização da palavra, através da interação entre os participantes. Cabe ressaltar que as Oficinas foram idealizadas não como ações de educação formativa de caráter conteudista, mas para atender a um público bem diversificado, que inclui em seu escopo pessoas de diferentes níveis de letramento.

\section{Estrutura Metodológica das Oficinas de ReEducação Ambiental}

As oficinas pedagógicas apresentam como estrutura metodológica uma sequência lógica de eventos que envolvem inicialmente, dinâmicas de acolhida ou entrosamento, seguidas da reflexão de um ou mais temas relacionados ao objetivo didático proposto e conta com o auxílio de recursos didáticos, além da realização de atividades práticas, característica indelével da própria ideia de oficina e avaliação final do processo. (FIGUEIREDO et al. 2006). As Oficinas de Reeducação Ambiental são desenvolvidas conforme estrutura metodológica explicitada pelos autores (Tabela 1).

Tabela 1: Estrutura pedagógica das Oficinas de Reeducação Ambiental. $X=$ ocorrência; - = ausência.

\begin{tabular}{|c|c|c|c|c|c|}
\hline $\begin{array}{c}\text { Estrutura } \\
\text { metodológica- } \\
\text { Oficina pedagógica }\end{array}$ & $\begin{array}{c}\text { Dinâmica } \\
\text { de } \\
\text { acolhida }\end{array}$ & $\begin{array}{c}\text { Temas } \\
\text { para } \\
\text { reflexão }\end{array}$ & $\begin{array}{c}\text { Atividade } \\
\text { prática }\end{array}$ & $\begin{array}{c}\text { Recursos } \\
\text { didáticos }\end{array}$ & Avaliação \\
\hline $\begin{array}{c}\text { Oficina de Reeducação } \\
\text { Ambiental }\end{array}$ & $\mathrm{X}$ & $\mathrm{X}$ & $\mathrm{X}$ & $\mathrm{X}$ & $\mathrm{X}$ \\
(Nov/2004-set/2008) & $\mathrm{X}$ & $\mathrm{X}$ & - & $\mathrm{X}$ & $\mathrm{X}$ \\
\hline $\begin{array}{c}\text { Oficina de Reeducação } \\
\text { Ambiental } \\
\text { (Set/2008-set/2018) }\end{array}$ & $\mathrm{X}$ & & & \\
\hline
\end{tabular}

Fonte: Quadro elaborado pelos autores a partir de Figueiredo et al. (2006). Dados obtidos nos registros das Oficinas - Arquivos do NEA-IBAMA/AM. 
A partir do acompanhamento das Oficinas verificou-se que as dinâmicas de grupo cumprem o intuito de fomentar a interação entre os participantes, favorecendo o relacionamento interpessoal. Para Freire (1998), tais ações propiciam o vínculo e a participação social, quando construídas de forma horizontal, priorizando o diálogo. Daí a importância das dinâmicas de grupo, no sentido de incluir o educando ao grupo. Tais aspectos foram evidenciados nas falas dos educandos e palestrantes que acompanhamos:

"Porque a oficina é uma maneira de adquirirmos conhecimento para dialogar com as pessoas que só querem discriminar pela sua ignorância."

(Educando 13. 32 anos. Entrevista realizada no dia 24/11/2015).

"O diálogo sem muitos termos técnicos e com uma explanação bem simples e clara ajuda a romper a resistência inicial da participação obrigatória. Percebemos isso durante as Oficinas."

(Palestrante 02. Entrevista realizada no dia 25/11/2015).

Freire (1998) salienta que a relação dialógica é essencial ao processo de ensino-aprendizagem, à medida que a interação possibilita a construção de um saber elaborado a partir da compreensão do objeto: "falar com clareza sobre o objeto, é incitar o aluno a fim de que ele, com os materiais que ofereço, produza a compreensão do objeto, em lugar de recebê-la, na íntegra, de mim" (FREIRE, 2002, p.133-134).

Neste sentido, a dinâmica de grupo é um recurso utilizado para trabalhar o processo de ensino-aprendizagem, de forma a considerar todos os envolvidos, como sujeitos do processo. A dinâmica de grupo objetiva:

“(...) estimular a produção do conhecimento e a recriação deste conhecimento tanto no grupo/coletivo quanto no indivíduo/singular, uma vez que a técnica da dinâmica não é um fim, mas um meio é uma ferramenta a ser usada" (GONÇALVES; PERPÉTUO, 2005, p.2).

Para Tavares e Lira (2001), as dinâmicas, enquanto mecanismo de articulação entre teoria e prática, podem melhorar o conteúdo e os métodos de ensino e influenciar qualitativamente no desenvolvimento dos envolvidos. Para os autores, as dinâmicas de grupo podem ser classificadas em quatro tipos: dinâmicas de apresentação; dinâmicas de descontração; dinâmicas de aplicação e dinâmicas de avaliação (Tabela 2) 
Tabela 2: Tipos de dinâmicas de grupo e seus objetivos.

DINÂMICAS DE GRUPO

Dinâmica de Apresentação

Dinâmica de Descontração

Dinâmica de Aplicação

Dinâmica de Avaliação

\section{OBJETIVOS}

Suprimir tensões, propiciar um ambiente de aceitação, acolhida, entrosamento e cordialidade entre os participantes.

Descontrair e proporcionar o interesse do grupo por temas específicos com devida liberdade em seus comentários.

Contribuir para a aquisição do conteúdo, potencializando a sua assimilação pelos participantes.

Atribuir ao educando a responsabilidade de avaliar as atividades pedagógicas desenvolvidas, considerando suas sugestões para possíveis melhorias do processo.

Fonte: Adaptado de TAVARES, C.; LIRA, N., 2001.

A partir de dados levantados nos arquivos do NEA/IBAMA (2004 a 2018), bem como dos registros da observação participante nas Oficinas de Reeducação Ambiental foram analisadas as dinâmicas desenvolvidas como estratégias pedagógicas e suas contribuições para melhorar o processo de ensino.

A presença de dinâmicas de apresentação; descontração; aplicação e avaliação é frequente. A dinâmica de apresentação esteve presente no início de todas as edições realizadas no período estudado (2004 a 2018). As dinâmicas de avaliação também foram frequentes (Tabela 3).

Tabela 3: Principais dinâmicas de grupo desenvolvidas nas Oficinas, no período de 2004 a 2018, classificadas por tipo e objetivo pedagógico, segundo Tavares e Lira, 2001.

\begin{tabular}{|c|c|c|c|}
\hline DINÂMICA & $\begin{array}{l}\text { TIPO DE } \\
\text { DINÂMICA }\end{array}$ & OBJETIVO PEDAGÓGICO & $\begin{array}{l}\text { EDIÇÃO/MÊS/ANO } \\
\text { DE REALIZAÇÃO } \\
\text { DAS OFICINAS }\end{array}$ \\
\hline Quem sou eu? & Apresentação & $\begin{array}{l}\text { Facilitar a convivência e estabelecer } \\
\text { a supremacia dos interesses } \\
\text { coletivos sobre os pessoais. }\end{array}$ & $\begin{array}{l}1 \stackrel{a}{a} / \text { nov./2004 a } \\
97 \mathrm{a} / \mathrm{set} . / 2018\end{array}$ \\
\hline A borboleta & Aplicação & $\begin{array}{l}\text { Aplicar a temática "Os } \\
\text { descompassos do } \\
\text { desenvolvimento" }\end{array}$ & $1 \stackrel{a}{a} /$ nov./2004 \\
\hline $\begin{array}{l}\text { Que bicho você } \\
\text { gostaria de ser? }\end{array}$ & & $\begin{array}{l}\text { Aplicar a temática: "A questão da } \\
\text { fauna" }\end{array}$ & $\begin{array}{l}\text { 44a } / \text { nov.2012; } \\
\text { 97a/set./2018 }\end{array}$ \\
\hline $\begin{array}{l}\text { Dinâmica da } \\
\text { bola }\end{array}$ & Descontração & $\begin{array}{l}\text { Facilitar o diálogo entre os } \\
\text { participantes }\end{array}$ & 3ª/jun./2005 \\
\hline Certas coisas & Avaliação & $\begin{array}{l}\text { Avaliar o nível de sensibilização dos } \\
\text { participantes ao final das oficinas }\end{array}$ & $\begin{array}{l}\text { 15a/mar./2009 a } \\
97 \text { aset../2018; }\end{array}$ \\
\hline
\end{tabular}

Fonte: NEA/IBAMA-AM. Elaborado pelo autor. 
A dinâmica de avaliação, segundo esses autores tem por objetivo contribuir para que os educandos avaliem o desenvolvimento do ensino e, ao final do processo, apresentem sugestões para possíveis melhoramentos. Neste tipo de dinâmica, não cabe avaliar se o conteúdo foi devidamente assimilado pelo educando, mas é ele quem tem a responsabilidade e a autonomia para avaliar o que precisa ser melhorado no desenvolvimento das temáticas durante as Oficinas.

Cabe ressaltar que as Oficinas de Reeducação Ambiental foram idealizadas não como ações de educação formativa de caráter conteudista, mas para atender a um público bem diversificado, que inclui em seu escopo pessoas de diferentes níveis de letramento, com o objetivo de promover sensibilização e reflexão acerca dos problemas ambientais e suas consequências para o coletivo.

Assim, as temáticas ambientais foram desenvolvidas de maneira a facilitar o diálogo e a troca de informação entre os participantes, respeitando sua opinião e considerando suas sugestões para a melhoria da abordagem das temáticas ambientais, atribuindo ao educando responsabilidades por avaliar seu próprio processo de ensino-aprendizagem, com vistas ao desenvolvimento de sua autonomia.

A inversão de papéis ao atribuir ao educando a responsabilidade por avaliar o seu próprio processo de ensino-aprendizagem remete à pedagogia da autonomia: "No fundo, o essencial nas relações entre educador e educando, entre autoridade e liberdade, entre pais, mães, filhos e filhas é a reinvenção do ser humano no aprendizado de sua autonomia" (FREIRE, 2002, p.56).

Freire (2002) se refere à reinvenção do ser humano no aprendizado da autonomia, não como propunha o pensamento iluminista, promovida pela razão com seus atributos transcendentais a priori, como pretendia a filosofia de Kant (2005), mas promovida a partir da ação e, sobretudo, da reflexão dialética sobre o mundo.

A influência freireana é perceptível, não só na forma como foi estruturada a proposta pedagógica das Oficinas, mas se torna patente, quando observada a forma de tratamento dispensada aos palestrantes, registrados em todas as ementas das Oficinas, que acompanhamos como "Facilitadores".

Na proposta freireana, o facilitador da autonomia é aquele que viabiliza ao educando situações nas quais ele deve se responsabilizar pelo seu próprio processo de ensino-aprendizagem, proporcionando situações em que o educando possa desenvolver sua autonomia.

A Este respeito é preciso desmistificar a ideia erroneamente difundida no meio educacional de que o professor facilitador é aquele que facilita a aprovação do aluno, pois isso não faz sentido nesta proposta. É preciso também esclarecer que o facilitador da autonomia é aquele que consegue proporcionar ao educando situações onde o mesmo possa tomar para si a responsabilidade pelo seu próprio processo de construção da autonomia. 
Neste sentido, a dinâmica de avaliação cumpre a tarefa de propiciar ao educando a condição de avaliador do seu próprio processo de aprendizagem, como forma de fomento ao exercício da autonomia, à medida que este toma para si a função de avaliar, argumentar, sugerir e criticar o processo, com vistas a sua melhoria.

Como desdobramento desta e de outras dinâmicas avaliativas, ocorrem modificações significativas na abordagem da temática "A Questão da Fauna", que passa a realizar, a partir de novembro de 2012, a dinâmica de aplicação "Que bicho você gostaria de ser?". Neste sentido, faz-se necessário destacar a persistente busca por aprimoramento do processo educativo por parte da equipe do Núcleo de Fauna Silvestre (NUFAS) e Núcleo de Educação Ambiental (NEA) do IBAMA - AM, com vistas a promover uma EA efetiva e reduzir a incidência de crimes contra a fauna.

Entre os crimes praticados pelos educandos atendidos nas Oficinas, identificou-se justamente aqueles relacionados à morte, perseguição e caça de espécimes da fauna silvestre, nativos ou em rota migratória, ou ainda a manutenção clandestina de animais silvestres em cativeiros, ou destinados à venda, em sua maioria aves e quelônios, tipologia criminal prevista no Art. 29 da Lei 9.605/98, conhecida como Lei dos Crimes Ambientais (LCA).

Daí a importância da dinâmica "Que bicho você gostaria de ser?", classificada como dinâmica de aplicação, com o objetivo de aplicar a temática "Maus-tratos contra animais silvestres", para evitar a reincidência de crimes contra a fauna. Percebe-se que essa dinâmica foi idealizada e realizada de maneira a potencializar a assimilação da temática pelos participantes.

A problematização da questão se dá em uma sequência didática de ensino-aprendizagem, que acaba por colocar o educando no lugar daquele animal, que ele se orgulha e gostaria de ser. Todavia, ao final da dinâmica, ele percebe, através de imagens, que aquele animal sofre maus-tratos ou é alvo da cobiça de traficantes de animais silvestres.

"A dinâmica 'Que animal você gostaria de ser? 'coloca a pessoa na pele do animal, sensibiliza para algumas situações que vivenciamos com os animais aqui no CETAS (Centro de Triagem de Animais Silvestres, grifo nosso) e que a gente apresenta durante a palestra". (Palestrante 06. Entrevista dia 24/11/2015).

"Percebemos claramente que as Oficinas se tornam efetivas quando, ao final de cada Oficina, a gente ouve as manifestações dos apenados, declinando suas posições e muitos se dispõem a trabalhar como voluntários, afirmando que as Oficinas se tornaram referências para as suas vidas". (Coordenador 01. Entrevista realizada no dia 22/12/2015). 
Essa abordagem dada ao tema "Maus-tratos contra animais silvestres" é um excelente exemplo de dinâmica do tipo aplicação, que objetiva a mudança de percepção, valores e atitudes, e que, além de aliar teoria e prática, pode melhorar o conteúdo ministrado, os métodos de ensino e influenciar qualitativamente no desenvolvimento dos envolvidos, independentemente do nível de escolaridade.

A partir da análise das entrevistas, foi possível perceber alguns aspectos que indicam a forma como os educandos interagem nesse espaço educativo, bem como analisar como esta prática educativa contribui para mudanças afetivas significativas, a ponto de contribuir para potencializar o agir e o pensar ético em relação às questões ambientais.

"Acredito que se todos tivessem uma oportunidade como esta, o meio ambiente não estaria tão degradado. Estou muito contente em ter a oportunidade de aprender". (Educando 01, 31 anos, 71 Edição da Oficina, 24/11/2015).

"Pensei que era só repressão! Estou gostando muito daqui e vou trazer os meus filhos e funcionários para conhecer também". (Educando 68, 58 anos, 72ª Edição da Oficina, 14/12/2015).

$\mathrm{Na}$ relação desenvolvida entre coordenadores, palestrantes e educandos durante as Oficinas ocorrem constantes intervenções feitas por parte dos educandos, que, através de depoimentos, denúncias ou relatos de vida, expressam os seus anseios, a sua gratidão ou inconformismo por estar ali.

"Gostei, mas ainda acho que pode ser feito mais pelo cidadão!" (Educando 27, 49 anos, 71 å Edição da Oficina, 24/11/2015).

"Eu estou aqui hoje por falta de humildade de um funcionário do IBAMA, que não teve diálogo, mas fora isso o trabalho de vocês aqui na oficina está ótimo". (Educando 12, 39 anos, 71ª Edição da Oficina, 24/11/2015).

"Estou revoltado, porque poderia estar trabalhando". (Educando 44, 68 anos, 72ª Edição da Oficina, 14/12/2015).

"Estou me sentindo muito bem, apesar do motivo de estar aqui, estou grata porque esta oficina está sendo uma grande oportunidade de conhecimento e aprendizado". (Educando 44, 51 anos, $72^{a}$ Edição da Oficina, 14/12/2015).

Fica claro, a partir das falas dos participantes, que o tipo de relações desenvolvidas durante as Oficinas estimula o diálogo, fortalece o vínculo participativo e uma maior inclusão do indivíduo ao grupo, à medida que este pode falar abertamente e expressar seus afetos, anseios e inquietações. 
Com base nessas observações, percebe-se claramente a influência de Freire (1998) no modo horizontal de condução das relações pelos coordenadores e palestrantes durante as atividades, o que explica o posicionamento participativo, crítico e questionador dos educandos, que revela o caráter democrático das relações ali desenvolvidas: "não é falando aos outros, de cima para baixo, (...) que aprendemos a escutar, mas é escutando que aprendemos a falar com eles" (FREIRE, 1998, p.127).

A boa expectativa de participação verificada no primeiro dia das Oficinas enquanto possibilidade de construção de novos saberes e práticas foi perceptível entre os participantes, que se mostraram, desde o início, propensos a uma maior interação. Isso nos remete à afirmação de Maffesoli (2001) acerca do papel da interação. Para este autor, é na interação que se dá a comunhão, troca de saberes e a circulação de signos.

Em outra análise, foi possível classificar e quantificar os motivos mencionados pelos educandos para explicar como estavam se sentido em relação à participação nas Oficinas (Tabela 4)

Tabela 4: Categorias de motivos que explicam os afetos dos educandos ao final da participação

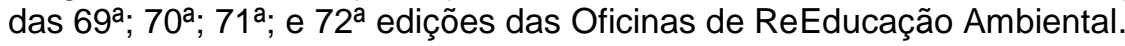

\begin{tabular}{|c|c|}
\hline MOTIVOS MENCIONADOS PELOS ALUNOS & $\begin{array}{c}\stackrel{\text { № }}{ }{ }^{2} \\
\text { OCORRÊNCIAS }\end{array}$ \\
\hline $\begin{array}{l}\text { Relacionados à aquisição de novos conhecimentos (Ensino-aprendizagem) } \\
\checkmark \text { Alegre, com os conhecimentos que foram desenvolvidos e aprendidos. } \\
\checkmark \quad \text { Animado, porque tiramos várias dúvidas e aprendemos mais sobre o nosso } \\
\\
\checkmark \quad \text { ambiente. } \\
\quad \text { Animado, porque independente do motivo que me trouxe aqui é uma grande } \\
\quad \text { oportunidade de conhecimento e aprendizado. } \\
\checkmark \quad \text { Satisfeita, com o conhecimento que adquiri. }\end{array}$ & 18 \\
\hline $\begin{array}{l}\text { Relacionados à inserção social (Ressocialização) } \\
\checkmark \quad \text { Animado e extremamente feliz, fazendo, partilhando, satisfeito. } \\
\checkmark \quad \text { Alegre, porque aprendi muito e tive a oportunidade de conhecer novas pessoas e } \\
\quad \text { fazer boas amizades. } \\
\checkmark \quad \text { Alegre, porque eu adquiri vários conhecimentos e conheci várias pessoas. } \\
\checkmark \quad \text { Alegre, pois tive acesso a novas informações e tive a oportunidade de conhecer } \\
\quad \text { novas pessoas. }\end{array}$ & 06 \\
\hline $\begin{array}{l}\text { Relacionados à intenção de disseminar o conhecimento (Agentes Multiplicadores) } \\
\checkmark \quad \text { Alegre, por estar aqui aprendendo muitas coisas sobre meio ambiente, } \\
\text { fortalecendo meus conhecimentos para compartilhar com muitos. } \\
\checkmark \quad \text { Animada, porque fui presenteada com todas as palestras, pois o conhecimento } \\
\text { que adquiri vou repassar para vizinhos e familiares. } \\
\checkmark \quad \text { Animado, porque agora eu posso passar para os meus vizinhos e amigos para } \\
\text { não maltratarem os animais e não fazer queimadas nos quintais. } \\
\checkmark \quad \text { Tranquilo, porque adquirimos conhecimento para dialogar. }\end{array}$ & 04 \\
\hline $\begin{aligned} & \text { Relacionados a condicionantes externos (Alheios à Oficina) } \\
& \checkmark \text { Revoltado, não consigo trabalhar com autonomia. } \\
& \checkmark \text { Triste, porque poderia estar trabalhando. } \\
& \checkmark \text { Desapontado, acho que precisa ser feito mais pelo cidadão também em outras } \\
& \text { áreas. }\end{aligned}$ & 03 \\
\hline
\end{tabular}

Fonte: Dados da sistematização da pesquisa

Revbea, São Paulo, V. 13, № 4: 30-50, 2018. 
Os motivos explicitados pelos educandos que explicam seus afetos ao final das Oficinas foram agrupados em quatro categorias: 1. Motivos relacionados à aquisição de novos conhecimentos (Aquisição de Conhecimento); 2. Motivos relacionados à inserção social (Ressocialização); 3 . Motivos relacionados à intenção de disseminar o conhecimento (Disseminação de Conhecimento); e 4. Motivos relacionados a condicionantes externos (Alheios à Oficina).

Com base nesses resultados, podemos caracterizar as Oficinas como espaços para: 1. Aquisição de novos conhecimentos e efetividade no processo de ensino-aprendizagem; 2. Promoção da inserção social; e 3. Formação de agentes multiplicadores dos conhecimentos adquiridos durante as Oficinas.

As Oficinas proporcionam mudanças nos afetos dos educandos, que potencializam o pensar e o agir, necessários para uma possível e desejável mudança na práxis dos participantes. A partir dos depoimentos expressos durante as Oficinas, percebe-se que o educando se configura como um ser que se constrói e reconstrói a partir das interações que estabelece consigo mesmo, enquanto indivíduo, com o outro, enquanto membro da sociedade, bem como com o mundo que o cerca, enquanto ser humano (Figura 3).

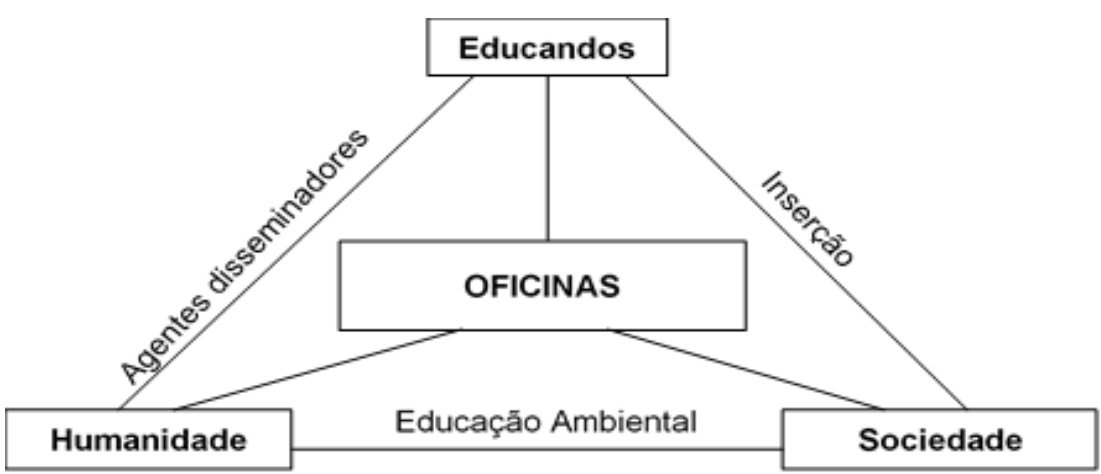

Figura 03: Anel tetralógico elaborado a partir dos motivos explicitados pelos educandos que explicam seus afetos ao final das Oficinas. Fonte: Adaptado de Morin (2002).

Era esperado que através do contato com novos conhecimentos, teorias e experiências, mas, sobretudo, pela mudança dos seus aspectos ético-afetivos, que o educando viesse a ter uma ação ou práxis diferente daquela anteriormente praticada. A esse respeito, Konder (1992) afirma que a práxis é a ação que para se fundamentar de maneira mais consequente precisa, necessariamente, da reflexão, do autoquestionamento e da teoria. À medida que a teoria remete à ação, possibilita enfrentar o desafio de verificar seus acertos e desacertos, confrontando-os com a prática.

Para Espinosa (1997), a mudança no agir e no pensar humano só ocorre quando há afetos envolvidos, à medida que um afeto mais forte se impõe, aumentando ou diminuindo sua potência de agir e de pensar. Esse autor 
reconhece a alegria e a tristeza como dois dos afetos fundamentais, sendo a alegria, para este autor, a consequência dos encontros ou acontecimentos que potencializam o agir e o pensar humano, e a tristeza o resultado dos encontros ou acontecimentos que diminuem essa potencialidade. Em Espinosa (1997), a transição entre afetos pode ocorrer de forma benéfica ou não. Neste sentido, ser afetada seria passar de uma perfeição menor para uma maior (alegria) ou de uma perfeição maior para uma menor (tristeza).

Dessa forma, os afetos estão diretamente relacionados ao agir ético, enquanto esforço para fortalecer aqueles afetos alegres e enfraquecer os tristes.

Para Mafessoli (2009, p. 101), é no contexto comunitário dos sentimentos e dos afetos que o corpo encontra seu lugar. Para este autor é preciso "(...) reconhecer que a vida é feita também de um realismo sensível: do compartilhamento das emoções, dos afetos e outras paixões comuns". De acordo com Morin (2006), a afetividade pode fortalecer a construção do conhecimento ou até mesmo extingui-lo. Por meio dessa estreita relação, a capacidade de raciocinar pode ser diminuída ou, até mesmo, destruída pelo déficit de emoção, ou enfraquecimento da capacidade de reagir emocionalmente e isso pode estar, segundo $o$ autor, na raiz de comportamentos irracionais.

Portanto, com base no exposto é possível concluir que essas Oficinas são capazes de promover uma nova práxis, de forma a aprimorar o indivíduo, no sentido de ressocialização e capacitação por meio da Educação Ambiental. E, além disso, possuem grande potencial no cumprimento de seu objetivo em evitar reincidência de crimes ambientais, bem como oportunizar a construção de novos saberes e valores.

\section{Macrotendências Político-Pedagógicas de Educação Ambiental: Temas Abordados}

A partir da análise dos temas ambientais constantes dos registros das ementas das Oficinas, bem como da forma de abordagem dada à temática por parte dos palestrantes entrevistados, foi possível vincular os temas abordados às três Macrotendências Político-Pedagógicas de EA propostas pelos autores. Os temas ambientais trabalhados nas 97 edições das Oficinas de Reeducação Ambiental foram previamente escolhidos para atender ao perfil da turma, considerando o tipo de crime com maior número de incidência entre os educandos de cada edição. Além disso, a supressão ou a inserção de temas também se dá a partir da disponibilidade dos palestrantes, cuja participação é de caráter voluntário.

Esses palestrantes se constituem em uma equipe interdisciplinar e interinstitucional constituída para abordar um conjunto de temas distintos em cada uma das edições das Oficinas. Levando em consideração esse aspecto, identificamos 27 temas ambientais, a partir da análise do conjunto de temas 
abordados nas Oficinas realizadas no período de novembro de 2004 a setembro de 2018.

Entre os temas ambientais mais frequentes estão: "A proteção à fauna", presente em 93\% das edições e "Poluição sonora" (91,7\%). Os temas "Cidadania e meio ambiente" (77,8\%); "Queimadas urbanas" (66,7\%); "A questão da floresta" $(62,5 \%)$; e "Licenciamento ambiental" (45,8\%) também foram abordados com frequência nas Oficinas no período estudado. A alta frequência desses temas é justificada não só por sua relevância, mas devido aos mesmos serem abordados por servidores do NUFAS/IBAMA-AM e SEMMAS, que sempre estiveram envolvidos com a realização das Oficinas.

Segundo Layrargues e Lima (2011), embora haja uma aparente homogeneização da EA no Brasil, como campo de conhecimento, esta apresenta práticas distintas, que podem estar vinculadas a uma das três Macrotendências Político-Pedagógicas de EA, são elas: Conservacionista; Pragmática e Crítica.

A Corrente Conservacionista de EA, segundo os autores, abrange as Correntes Conservacionistas; Ambientalistas e a Alfabetização Ecológica, que objetivam conservar os recursos naturais, tendo como móvel a alfabetização e a administração dos recursos naturais, sem, contudo, reconhecer a dimensão socioambiental. Para Sauvé (2005), a Corrente Conservacionista de EA tem caráter recursista, ou seja, objetiva a conservação dos recursos naturais.

Em oposição às Tendências Conservadoras, a Macrotendência Crítica procura politizar e problematizar as contradições da sociedade, por meio do fomento à cidadania e à participação popular crítica e no enfrentamento dos problemas ambientais. Essa Tendência surge para atender às demandas políticas e sociais do pós-ditadura no Brasil, bem como às demandas da Conferência Rio 92. (LAYRARGUES; LIMA, 2011). Atualmente, essa Macrotendência encontra guarida nos posicionamentos político-pedagógicos da teoria freireana, bem como nos fundamentos filosóficos da Teoria Crítica.

A Tendência Pragmática abarca as Correntes de EA para o desenvolvimento sustentável e as Correntes de EA para o Consumo Sustentável. Segundo Layrargues e Lima (2014), com essa Macrotendência ocorre um deslocamento no propósito da EA, que desloca as intenções educativas para o sentido pragmático de mercado como um meio para a correção das imperfeições da trilogia "produção-consumo-resíduos", sem indagar acerca da distribuição desigual dos custos e benefícios, relacionados à obsolescência dissimulada, consumo alienado e descartabilidade.

A partir da análise dos temas ambientais constantes dos registros das ementas das Oficinas de Reeducação Ambiental (NEA/IBAMA, 2018), bem como da forma de abordagem dada à temática por nove palestrantes entrevistados neste estudo, foi possível identificar as Macrotendências Político-Pedagógicas de EA: Conservacionista, Crítica e Pragmática (LAYRARGUES; LIMA, 2011). 
Tabela 5: Distribuição dos temas abordados nas Oficinas por Tendência Político-Pedagógica de EA (LAYRARGUES; LIMA, 2011). $\mathrm{N}=27$.

\begin{tabular}{|c|c|}
\hline TEMAS ABORDADOS & $\begin{array}{c}\text { № DE OCORRÊNCIAS/ } \\
\text { FREQUÊNCIA (\%) }\end{array}$ \\
\hline $\begin{array}{l}\text { Relacionados à Macrotendência Conservacionista de EA } \\
\text { Educação Ambiental } \\
\text { Áreas Protegidas e Unidades de Conservação; Proteção à } \\
\text { Fauna Silvestre (caça, tráfico, extinção de espécies); A Questão } \\
\text { da Pesca (manejo, piracema e defeso); A Questão da Floresta; } \\
\text { Desmatamento e Queimada; Manejo da Fauna; Manejo de } \\
\text { Lagos e Quelônios; Manejo do Pirarucu; Mudanças Climáticas; } \\
\text { Gestão Ambiental/Competências; Licenciamento Ambiental; } \\
\text { Recursos Hídricos (água fonte de vida); Noções de Poluição; } \\
\text { Poluição Sonora; Poluição Hídrica. }\end{array}$ & $\begin{array}{c}15 / \\
(55 \%)\end{array}$ \\
\hline $\begin{array}{l}\text { Relacionados à Macrotendência Crítica de Educação } \\
\text { Ambiental } \\
\text { Cidadania e meio ambiente; A Questão Ambiental; A Questão } \\
\text { do Direito Ambiental; Relação ser Humano e Natureza; A } \\
\text { Importância das Leis na Organização Social e Econômica da } \\
\text { Sociedade; Educação x Degradação Ambiental; Saúde e } \\
\text { Ambiente; Posse Responsável (de cães e gatos, grifo nosso) }\end{array}$ & $\begin{array}{c}8 / \\
(30 \%)\end{array}$ \\
\hline $\begin{array}{l}\text { Relacionados à Macrotendência Pragmática de Educação } \\
\text { Ambiental } \\
\text { Queimadas Urbanas; Perigo Aviário; Fiscalização Ambiental; } \\
\text { Emergências Ambientais }\end{array}$ & $\begin{array}{c}4 / \\
(15 \%)\end{array}$ \\
\hline
\end{tabular}

Fonte: Dados da sistematização da pesquisa.

Dos 27 temas tratados nas Oficinas de Reeducação Ambiental, a maioria se enquadra na Macrotendência Conservacionista, evidenciando a importância da conservação, proteção e administração de recursos naturais, dentre eles a fauna, flora e recursos hídricos. A Macrotendência Crítica está presente em $30 \%$ e a Pragmática em 15\% dos temas abordados.

Apesar da Corrente Conservacionista, segundo Loureiro e Layrargues (2001), ter perdido a sua hegemonia no Brasil na década de 1990, os temas abordados nas Oficinas, evidenciam a importância da conservação, proteção e administração de recursos naturais, dentre eles fauna, flora e recursos hídricos no contexto amazônico, representativos dos tipos de crimes ambientais mais praticados.

Representam, ainda, o esforço conjugado entre os órgãos de defesa do meio ambiente, que, de forma integrada, contínua e sistemática vêm desenvolvendo temáticas em sua maioria conservacionistas, por mais 14 anos no Amazonas, embora nesta concepção de EA, não se reconheça a dimensão social do ambiente, em suas relações homem e natureza, ou ainda o enfrentamento político das desigualdades e injustiças socioambientais.

Outra atividade de caráter pedagógico que caracteriza as Oficinas consiste na realização de atividades práticas concebidas no projeto original (2004) e 
realizadas até $\mathrm{o}$ ano de 2008. A supressão das atividades práticas levou à redução na carga horária das Oficinas, antes distribuídas em 3 horas diárias, executadas em 5 dias e, a partir de então, reduzidas para 3 horas diárias desenvolvidas em 4 dias, totalizando 12 horas.

Tais atividades práticas eram desenvolvidas aos sábados e realizadas em espaços distintos daquele onde ocorriam as palestras. O que exigia certa infraestrutura, relacionada à logística de transporte, locais propícios ao desenvolvimento dessas atividades aos sábados e, sobretudo, de uma equipe de voluntários. Consistiam em ações de sensibilização como visitas a espaços públicos de cuidado a animais que sofriam maus-tratos ou locais de refúgio da fauna silvestre ( $3^{\mathrm{a}}$ e $8^{\mathrm{a}}$ edições); ações que colocavam os educandos no papel de agentes de sensibilização das questões ambientais junto à sociedade em

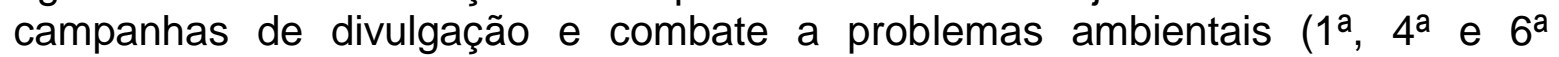
edições); e ações de participação ativa dos educandos em atividades favoráveis ao ambiente como no plantio de árvores e mutirões (2 $2^{\underline{a}}, 9^{\underline{a}}$ e $11^{\underline{a}}$ edições).

A não realização das atividades práticas, a partir de setembro de 2008, ocorreu em virtude de adequações realizadas naquele período, devido, entre outras coisas, à impossibilidade de parceria para a oferta de transporte e o caráter voluntário dos palestrantes e colaboradores. Essas práticas representaram um momento característico da própria ideia de oficina pedagógica. Portanto, sua consequente exclusão, em setembro de 2008, repercutiu drasticamente sobre aquilo que a caracterizava originalmente como oficina pedagógica.

As atividades práticas remetem às atividades desenvolvidas nas Oficinas e Corporações de Ofícios. Neste sentido, salienta-se que o conceito de oficina pedagógica retoma apenas os aspectos didático-pedagógicos das relações desenvolvidas entre mestre e aprendiz, ou entre as relações de mestrança e aprendizado, fica patente que da perícia didático-pedagógica daqueles mestres de ofícios dependia a qualidade da obra realizada pelos aprendizes.

Assim, sugere-se que as Oficinas de Reeducação Ambiental passem a ser denominadas de Curso de Reeducação Ambiental, ou que se mantenha a atual denominação de Oficinas, mas que seja viabilizada a reintrodução das atividades práticas, principal caraterística de uma oficina pedagógica. Sugere-se, ainda, que essas atividades sejam realizadas nos dias úteis da semana, para facilitar a adesão de um maior número de voluntários entre a equipe executora.

As diferentes abordagens de Educação Ambiental e as atividades práticas tornam as Oficinas de Reeducação Ambiental pedagogicamente exitosas, por possibilitarem a abordagem das questões ambientais por diferentes vertentes e viabilizarem o contato direto do educando com outros membros da sociedade em Campanhas de sensibilização (combate a queimadas, poluição sonora, defeso) e em ações efetivas de cuidado com o ambiente (plantio de árvores, cuidado a animais que sofreram maus-tratos etc. 
A não realização das atividades práticas, a partir de setembro de 2008, ocorreu em virtude de adequações realizadas naquele período, devido, entre outras coisas, à impossibilidade de parceria para a oferta de transporte e o caráter voluntário dos palestrantes e colaboradores.

Essas atividades práticas representaram um momento característico da própria ideia de oficina pedagógica. Portanto, sua consequente exclusão, em setembro de 2008, repercute drasticamente sobre aquilo que a caracteriza originalmente como oficina pedagógica.

As diferentes abordagens de Educação Ambiental e as atividades práticas tornam as Oficinas de Reeducação Ambiental pedagogicamente exitosas, por possibilitarem a abordagem das questões ambientais por diferentes vertentes e viabilizarem o contato direto do educando com outros membros da sociedade em Campanhas de sensibilização (combate a queimadas, poluição sonora, defeso) e em ações efetivas de cuidado com o ambiente (plantio de árvores, cuidado a animais que sofreram maus-tratos etc.).

\section{Considerações Finais}

As Oficinas de Reeducação Ambiental desenvolvidas na cidade de Manaus são realizadas por meio do esforço conjugado entre os órgãos de defesa do meio ambiente, sobretudo pela forma integrada, contínua e sistemática como as práticas pedagógicas foram conduzidas ao longo dos anos.

Os dados de sistematização da pesquisa revelam que o público-alvo das Oficinas é constituído, em sua maioria, por homens com escolaridade bem variada. A maioria possui o ensino médio e, em um dado momento, cometeram um crime ambiental que os compeliu a participar das Oficinas.

O caráter de construção de novos conhecimentos, reconhecido nos discursos dos próprios educandos, demonstra que os métodos e práticas pedagógicas utilizados nas Oficinas surtem os efeitos desejados. Constatamos que, nos últimos 14 anos, as Oficinas de Reeducação Ambiental foram mediadas por práticas pedagógicas que apresentam uma estrutura metodológica bem específica subdividida em: Dinâmicas de apresentação; Palestras temáticas; Atividades práticas e Dinâmicas de avaliação.

Suas dinâmicas cumprem o intuito de fomentar a interação e facilitar a compreensão dos temas ambientais por um público de diferentes níveis de escolaridade, além de propiciar ao educando a oportunidade de avaliar seu próprio processo de ensino-aprendizagem. Os temas abordados são representativos dos tipos de crimes ambientais que ocasionaram a participação compulsória nas Oficinas, além de revelar, em sua abordagem, a vinculação às Macrotendências político-pedagógicas "Conservacionista", "Crítica" e "Pragmática" de Educação Ambiental. 
As atividades práticas realizadas nas Oficinas de Reeducação Ambiental, característica indelével das oficinas pedagógicas, que deixaram de ser executadas em setembro de 2008, eram estratégias metodológicas executadas, inicialmente, com grande êxito pedagógico, por proporcionar ao educando a incumbência de disseminar o conhecimento por ele construído e reconstruído, a partir de suas interações nas dinâmicas e palestras temáticas, através da participação em campanhas e mutirões ambientais.

Assim, considerando que essas atividades práticas foram suprimidas da metodologia, sugere-se que a Oficina de Reeducação Ambiental passe a ser denominada de Curso de Reeducação Ambiental. Porém, vale ressaltar que a reinclusão das atividades práticas, preferencialmente realizadas nos dias úteis da semana, para facilitar a adesão de um maior número de voluntários entre a equipe executora, seria de grande relevância na composição pedagógica original deste processo, que se demonstrou bastante efetivo.

O crime de recepção ou aquisição de madeira ou carvão sem a exigência de licença do vendedor (Art. 46 da Lei 9.605/98 - LCA) foi o que obteve maior incidência entre os crimes ambientais praticados no período estudado, seguido de construções, reformas, ampliações, instalações ou funcionamento, obras ou serviços potencialmente poluidores (Art. 60 da LCA) e morte, perseguição, caça de espécimes da fauna silvestre, nativos ou em rota migratória (Art. 29 da LCA).

Os educandos, em sua maioria, atribuem a mudança de afetos durante as Oficinas a motivos relacionados à aquisição de novos conhecimentos, seguido dos motivos relacionados aos mecanismos de ressocialização. A troca de afetos levou alguns educandos a explicitarem sua intenção em disseminar o conhecimento adquirido nas Oficinas, passando a atuarem como agentes multiplicadores.

A pesquisa revelou, também, que os educandos não se sentem penalizados em participar da Oficina, a ponto de convidar amigos e familiares para conhecer e participar das atividades ali desenvolvidas.

Constata-se, de forma clara, que as Oficinas de Reeducação Ambiental são efetivas como alternativa penal e modalidade diferenciada de EA, voltada ao atendimento de um público também diferenciado.

Com base na verificação dos resultados positivos do processo de ensinoaprendizagem para a aquisição de novos conhecimentos, na intenção explicitada pelos educandos em disseminar o conhecimento adquirido e nos aspectos afetivos e sociais envolvidos, reiteramos, com este estudo, o importante papel desempenhado pelas Oficinas de Reeducação Ambiental nos últimos 14 anos na cidade de Manaus. 


\section{Referências}

ANTONIO, A. C. Ecoletânea: subsídios para a formação de uma consciência jurídico-ecológica. Manaus: Editora Valer, 2000, p. 75

ANTONIO, A.C. A Conciliação como Solução dos Problemas Ambientais. Revista CEJ, Brasília, o 32, p. 6-11, jan./mar. 2006. Disponível em: < http://www.jf.jus.br/ojs2/index.php/revcej/article/viewArticle/695 $>$ Acesso em: 04/10/2018.

AZEVEDO, A. A Educação Ambiental e sua aplicação na substituição da pena nos crimes ambientais. Tese, São Paulo: ano V, v.9. 1ํsemestre, 2008. Disponível em: $<$ http://www.cantareira.br/thesis2/ed 9/05 ana celia.pdf> Acesso em: 04/10/18.

BRASIL. Lei no 9.099, de 26 de setembro de 1995. Dispõe sobre os Juizados Especiais Cíveis e Criminais e dá outras providências. Diário Oficial da União. Brasília. DF, 1995.

BRASIL. Lei no 9.605, de 26 de setembro de 1998. Dispõe sobre as sanções penais e administrativas derivadas de condutas e atividades lesivas ao meio ambiente, e dá outras providências. Brasília, DF: Diário Oficial da União, 1998.

BRASIL. Lei n. 9795, de 27 de abril de 1999. Dispõe sobre a Educação Ambiental. Política Nacional de Educação Ambiental. Brasília, 1999.

BARDIN, L. Análise de conteúdo. 70ํㅡㄹ ed. São Paulo: Martins Fontes, 2011.

ESPINOSA, B. Ética: demonstrada à maneira dos geômetras. Os Pensadores. Trad. Joaquim de Carvalho, Joaquim Ferreira Gomes e Antônio Simões. São Paulo: Nova Cultural, 1997.

FIGUEIREDO, M. et al. Metodologia de oficina pedagógica: uma experiência de extensão com crianças e adolescentes. Revista Eletrônica Extensão Cidadã. V. 2, 2006. Disponível em: <http://periodicos.ufpb.br/ojs2/index.php/extensaocidada/ article/view/1349> Acesso em: 06/05/2018.

FOUCAULT, M. Vigiar e punir: história da violência nas prisões. Petrópolis: Vozes, 2013.

FREITAS, V. A reeducação dos infratores ambientais em Manaus. Revista Consultor Jurídico, julho de 2011. Disponível em: <https://www.conjur.com.br /2011-jul-24/segunda-leitura-reeducacao-infratores-ambientais-manaus > Acesso em: 04/10/2018.

FREIRE, P. Professora sim, tia não. São Paulo, SP: Olho d'Água, 1998.

FREIRE, Paulo. Pedagogia da autonomia: saberes necessários à prática educativa. 8르 ed. Rio de Janeiro: Paz e Terra, 2002.

GONÇALVES, A.; PERPÉTUO, S. Dinâmica de grupo na formação de lideranças. Rio de Janeiro: DP\&A, 2005.

KANT, I. Crítica da Razão Pura. 5ª ed. Lisboa: Calouste, 2005.

KONDER. L. O Futuro da Filosofia da Práxis: o pensamento de Marx no século XX. Ed. Paz e Terra. 1992 
LAYRARGUES, P.; LIMA, G. As macrotendências político-pedagógicas da Educação Ambiental brasileira. Ambiente \& Sociedade. São Paulo; v. XVII, no 1, p. 23-40, jan/mar. 2014 Disponível em:

<http://www.scielo.br/pdf/asoc/v17n1/v17n1a03.pdf > Acesso em: 06/05/2018.

LAYRARGUES, P.; LIMA, G. Mapeando as Macrotendências políticopedagógicas da Educação Ambiental contemporânea no Brasil. In: VI Encontro Pesquisa em Educação Ambiental: a pesquisa em Educação Ambiental e a pós-graduação. Ribeirão Preto: USP, 2011. p. 01-15. Disponível em:

$<$ http://www.icmbio.gov.br/educacaoambiental/images/stories/biblioteca/educacao ambiental/Layrargues e Lima - Mapeando as macro-tend\%C3\%83\%C2\%AA ncias da EA.pdf> Acesso em: 06/05/2018.

LECEY, E. Direito Ambiental Penal Reparador. Composição e reparação do dano ao ambiente: reflexos no juízo criminal e a jurisprudência. Revista de Direito Ambiental, vol. 45, São Paulo: Editora Revista dos Tribunais, 2007. Disponível em:< https://bdjur.sti.jus.br/jspui/handle/2011/86364 .

LOUREIRO, C. : LAYRARGUES, P. Educação Ambiental nos anos 90. Mudou, mas nem tanto. In: Políticas Ambientais, 9 (5): 6-7, 2001. Disponível em: $<$ https://lieas.fe.ufri.br/download/artigos/ARTIGO-

EDUCACAO AMBIENTAL ANOS 90-2001.pdf > Acesso em: 06/05/2018.

MAFFESOLI, M. O imaginário é uma realidade. Entrevista concedida a Revista FAMECOS. Porto Alegre, n. 15, agosto, quadrimestral, 2001.

MAFFESOLI, M. A república dos bons sentimentos; tradução de Ana Goldberger. São Paulo: lluminuras: Itaú Cultural, 2009.

MEDEIROS J.; SILVA N. Penas e medidas alternativas e proteção ambiental: Reflexões para uma atuação judicial proativa. Anais do XVII Congresso Nacional do CONPEDI, realizado em Brasília - DF nos dias 20, 21 e 22 de novembro de 2008. Disponível em: < http://www.publicadireito.com.br/ conpedi/anais brasilia.html > Acesso em: 04/10/2018.

MORIN, E. A natureza da natureza. Porto Alegre: Sulina, 2002.

MORIN, E. Os saberes necessários à educação do futuro. São Paulo: Cortez, 2006.

RIBEIRO, L. S. A ineficácia da transação penal para a composição ambiental nos crimes ambientais. Boletim Jurídico. Ano XIV. № 1261. Edição № 156. Uberaba, MG. 2005. Disponível em: < www.boletimjuridico.com.br/doutrina/texto.asp?id=969 > Acesso em: 04/10/2018.

SAUVÉ, L. Uma cartografia das correntes em Educação Ambiental. In: SATO, M.; CARVALHO, I.C.M. Educação Ambiental: pesquisa e desafios. Porto Alegre: Artmed, p.17-44, 2005.

TAVARES, C.; LIRA, N. (Org.) Construindo uma cultura de paz: oficinas pedagógicas. Recife: Comunigraf, 2001. 